\title{
Estimation of L-5-Hydroxytryptophan in West African medicinal plant Griffonia simplicifolia Baill. by ultra performance liquid chromatography
}

\author{
Sethu R. KAVURI ${ }^{1 *}$ and Saratchandra B. MUKKAMALA ${ }^{2}$ \\ ${ }^{I}$ Member, American Association of Pharmaceutical Scientists, United States of America. \\ ${ }^{2}$ Department of Chemistry, GITAM University, Visakhapatnam-530 045, Andhra Pradesh, India. \\ *Corresponding author, E-mail: sethukavuri@gmail.com, Tel: +001-269-544-2506, \\ 4714 Golden Ridge Trl, Portage, MI-49024, USA.
}

\begin{abstract}
Ultra speed chromatographic analysis of L-5-Hydroxytryptophan with good efficiency was developed and validated using Ultra performance liquid chromatography (UPLC). Validated method is very sensitive and demonstrated good linearity, precision, accuracy, robustness and the stability indicative nature.

(c) 2010 International Formulae Group. All rights reserved.
\end{abstract}

Keywords: L-5-Hydroxytryptophan, UPLC method.

\section{INTRODUCTION}

Griffonia simplicifolia Baill.

(Caesalpinaceae) is an important West African medicinal plant containing high concentrations of L-5-Hydroxytryptophan (5HTP) which is an amino acid naturally produced by the human body. Griffonia extracts are recommended as dietary supplement (Murray, 1998). L-5-HTP enhances the activity of serotonin, a hormone produced by the brain. L-5-HTP has been shown to be effective in treating a wide variety of conditions, including mood disorders, fibromyalgia, insomnia, obsessive/compulsive disorders as well as eating disorders leading to obesity (Cangiano et al., 1992).

Since 5-HTP exhibited significant pharmacological activities, several scientists focused on the development of various analytical methods like liquid chromatographic methods with UV and mass detections (Sukala et al., 2005; Meek, 1976; Mefford and Buchard, 1980; Arneric et al., 1981; Calguri and Mefford, 1984; Yi et al., 1994; Lemaire and Adosraku, 2002; Petrits et al., 2001), spectrophotometry, fluorescence spectrometry (Tachiki and Aprison, 1975), gas chromatography (Catlabeni et al., 1972), and capillary electrophoretic methods (Takagai and Igarashi, 2003) were employed for the estimation of L-5-HTP.

In the current study, very rapid UPLC method was developed for the estimation of 5HTP in various sample matrices containing Griffonia simplicifolia extracts. The validated method is very sensitive, precise and accurate to identifying even minute quantities of 5HTP.

\section{MATERIALS AND METHODS \\ UPLC Instrumentation}

Waters® Acquity UPLC system with Binary Solvent Manager, Sample Manager 
and UV detector, Waters® Acquity UPLC BEH C18, $1.7 \mu \mathrm{m}, 2.1$ x $50 \mathrm{~mm}$ analytical column were used for the analysis and method validation. Empower® software was used for data processing and reporting. Evaluation was via peak areas with external standard calibration.

\section{Materials}

All the solvents and reagents used in this study were HPLC grade obtained from commercial sources. Excipients used in the preparations were pharmaceutical grade procured from commercial vendors. L-5Hydroxytryprophan reference material was purchased from Sigma-Aldrich Corporation (USA).

\section{Chromatographic conditions}

Isocratic elution was carried out with the following conditions:

- Mobile phase: Mixture of methanol and 10 $\mathrm{mM}$ sodium phosphate monobasic with $0.1 \%$ triethylamine at $\mathrm{pH} \quad 2.5 \quad(50: 50)$ filtered through $0.2 \mu \mathrm{m}$ membrane filter;

- Diluting solvent: Methanol and water (60:40);

- Flow rate: $0.5 \mathrm{~mL} / \mathrm{min}$;

- Wavelength: $275 \mathrm{~nm}$;

- Column temperature: $40{ }^{\circ} \mathrm{C}$;

- Injection volume: $5 \mu \mathrm{L}$;

- Run time: 2 minutes.

\section{Analysis}

\section{Raw material sample preparation}

About 1 gram of finely powdered raw material was extracted with about $50 \mathrm{~mL}$ of methanol three times, by refluxing in a round bottom flask connected to a water condenser. After evaporating all the solvent from the combined extracts, the residue was dissolved and transferred into a $100 \mathrm{~mL}$ volumetric flask with diluting solvent. Aliquot sample was filtered through $0.2 \mu \mathrm{m}$ membrane filter before injecting into the UPLC system.

\section{Preparation of dosage forms of samples}

Five dosage units were grounded to fine powder and quantitatively transferred into $100 \mathrm{~mL}$ volumetric flask. About $75 \mathrm{~mL}$ of diluting solvent was added to the flask and sonicated for 30 minutes and made up the volume with diluting solvent. Samples were filtered through $0.2 \mu \mathrm{m}$ membrane filter before injecting into the UPLC system.

\section{Standard preparations}

L-5-hydroxytryptophan reference standard solution was prepared by dissolving the reference material in diluting solvent to obtain a final concentration of $10 \mu \mathrm{g} / \mathrm{mL}$ of 5 HTP.

\section{Quantification of L-5-HTP}

Diluting solvent, Standard, Sample solutions were analyzed by UPLC. L-5-HTP concentration in the sample was quantified using the peak area in the sample preparations against the corresponding peak area of the standard preparation.

From the system suitability data (Table 1) and the chromatogram (Figure 1), it is evident that the proposed chromatographic conditions are selective to quantify L-5-HTP.

\section{Method validation}

The method for quantification of L-5Hydroxytryptophan was validated with regard to its selectivity, Linearity, precision, accuracy, stability, robustness, limit of detection and quantification.

Selectivity of the method was ascertained by exposing the samples containing L-5-HTP and vitamins to various conditions to establish the stability indicative nature of the method. All stressed samples were analyzed using a Photodiode Array detector. Mass balance range (92.3-99.8\%)

Table 1: Characteristic parameters for system suitability of the method.

\begin{tabular}{lc}
\hline System suitability parameter & L-5-Hydroxytryptophan (5-HTP) \\
\hline Capacity factor & 1.2 \\
Tailing factor & 1.0 \\
Theoretical plates & 80000 \\
Symmetry factor & 1.0 \\
$\%$ RSD in the standard & 0.1 \\
\hline
\end{tabular}




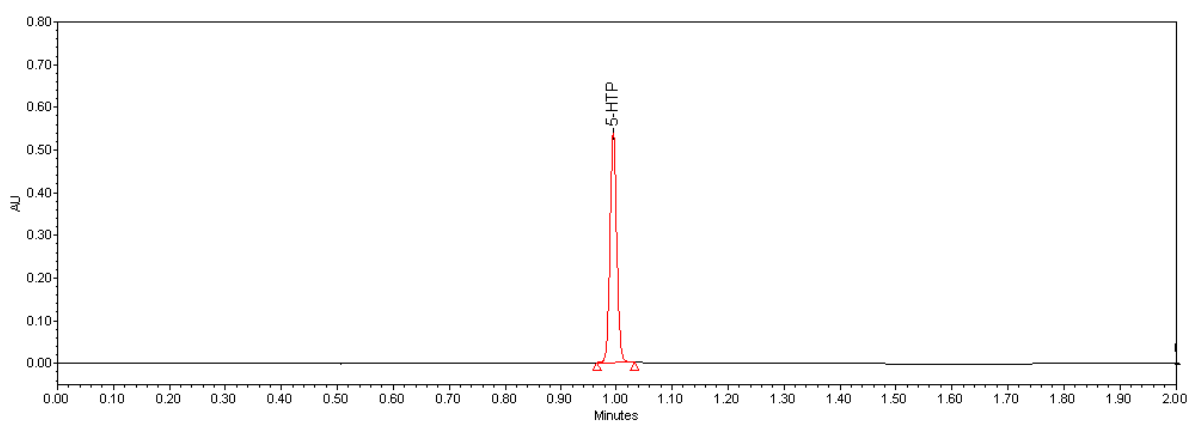

Figure 1: Typical chromatogram.

results and peak purity analysis (5-HTP purity angle and match angle values were less than the corresponding purity threshold and match threshold) in all the stressed samples confirmed that L-5-HTP was selective and had no interference in any of the stressed sample.

Linearity was evaluated by performing the analysis of six standard solutions containing L-5-Hydroxytryptophan in the concentration range of $0.1-500 \mu \mathrm{g} / \mathrm{mL}$. Concentrations and peak area were subjected to linear regression analysis to calculate the correlation co-efficient. The linearity of the calibration curve and adherence of the system to Beer's law was validated by high value correlation co-efficient of 0.999 for L-5-HTP.

Accuracy of the method was determined by calculating the recovery of L5-HTP. A known amount of L-5-HTP at 0.2 $\mu \mathrm{g} / \mathrm{mL}, \quad 200 \mu \mathrm{g} / \mathrm{mL}$ and $500 \mu \mathrm{g} / \mathrm{mL}$ concentration was added into a placebo sample and analyzed as per method. Recovery results ranging from 98.2-101.3\% with less than $2.0 \%$ variation coefficient across the concentration range indicated that the method was accurate.

The precision of the method was evaluated by analyzing six samples, replicated from a homogeneous sample composition on different days and using different equipments. Percent co-efficient of variation on intra-day and inter-day precision was found to be less than $2.0 \%$.

The limit of detection (LOD) and limit of quantitation (LOQ) were estimated by analyzing known concentrations of L-5-HTP until the signal to noise ratios were $3: 1$ and 10:1 respectively. The LOD and LOQ of L-5-
HTP were found to be 0.01 and $0.03 \mu \mathrm{g} / \mathrm{mL}$ respectively.

Solution stability was verified by preparing three standard solutions and three sample solutions, stored at ambient conditions and analyzed at various time points against a freshly prepared standard at each test point. Both standard and sample solutions were stable for at least 3 days. Absolute percent difference from initial results to the different test points found to be less than $1.0 \%$.

Robustness of the method was verified by deliberately varying the normal conditions, changes to methanol concentration in mobile phase by $\pm 5 \%$ and changes to the $\mathrm{pH}$ of mobile phase by \pm 0.2 units did not significantly influence the quantification of L5-HTP and other system suitability requirements.

\section{Conclusion}

A rapid ultra fast reverse-phase UPLC method was developed and validated for the determination of L-5-HTP. The proposed method is sensitive, selective, linear, precise, accurate and robust. The method can be used in the routine analysis of plant raw materials, plant extracts and finished dosages containing L-5-HTP even at very low concentrations.

\section{REFERENCES}

Murray NDM. 1998. "5-HTP-The Natural Way to Overcome Depression, Obesity and Insomnia". Bantom Books: New York.

Cangiano C, Ceci F, Cascino A, Del Ben M. 1992. Eating behavior and adherence to dietary prescriptions in obese subjects 
treated with 5-HTP. Am. J. Clin. Nutr., 56: $863-867$.

Sukala KB, Tummala R, Gottumukkala VS, 2005. HPLC estimation of 5-HTP in Griffonia simplicifolia extract. Asian $J$. Chem., 17(1): 506-510.

Meek JL, 1976. Application of inexpensive equipment for HPLC to assays for taurine, $\gamma$-aminobutyric acid and 5-HTP. Analytical Chemistry, 48: 375-379.

Mefford IN, Buchard JD, 1980. Determination of metabolites in rat brains and pineal tissue by reversed phase HPLC with electro chemical detection. J. Chrom., 181: 187-193.

Arneric SP, Goodale DB, Flynn JR, Long JP, 1981. Rapid and simple analysis of Dopa and 5-HTP using HPLC with electrochemical detection. Brain Research Bulletin, 6: 407-411.

Calguri EJ, Mefford IN, 1984. Femtogram detection limits for biogenic amines using microbore HPLC with electro chemical detection. Brain Research, 296: 156-159.

Yi YH, Liao WP, Lu X, 1994. Simultaneous determination of tryptophan, 5-HTP, 5- hydroxytrypamine, in human cerebrospinal fluid. J. Chrom. B., 661: 143-148.

Lemaire PA, Adosraku RK, 2002. An HPLC method for the direct assay of the serotinin precursor, 5-HTP in seeds of $G$. simplicifolia extracts. Phytochemical Analysis, 13: 333-337.

Petrirts K, Valleix A, Elfakir C, Dreux M, 2001. Simultaneous analysis of underivitazed chiral amino acids by LCMS using teicoplanins stationary phase. $J$. Chrom. A., 913: 313-340.

Tachiki KH, Aprison MH. 1975. Flourometric assay for 5-HTP with sensitivity in the picmole range. Analytical Chemistry, 47: 7-11.

Catlabeni F, Koslow SH, Costa E. 1972. GCMS assay of four indole alkylamines of rat pineal. Science, 178: 162-166.

Takagai Y, Igarashi S. 2003. Determination of ppb levels of tryptophan derivatives by capillary electrophoresis with homogeneous liquid-liquid extraction and sweeping method. Chemical and Pharmaceutical Bulletin, 51: 373-377. 